Reseña

\section{Mariano A. Bonialian. La América española: entre el Pacífico y el Atlántico. Globalización mercantil y economía política, 1580-1840. Ciudad de México, El Colegio de México, 2019, 446 págs., ISBN: 978-607-628-674-6.}

En la última década, Mariano Bonialian ha sido el historiador que más ha profundizado en el estudio de los intercambios entre Nueva España y Filipinas y entre Nueva España y el virreinato del Perú durante el periodo colonial. Su gran contribución reside, precisamente, en aflorar los estrechos vínculos entre ambas rutas comerciales, la transpacífica (legal pero atiborrada de fraude en sus 250 años de existencia) y la intervirreinal (vibrante y robusta durante largos periodos, a pesar de su pretendida ilegalidad impuesta en 1593). El galeón de Manila surcaba el océano anualmente para arribar a Acapulco repleto de sedas y cerámicas chinas, algodones indios y muebles japoneses, además de otros productos y manufacturas orientales y asiáticas. A su llegada, se celebraba una feria a la que acudían no solo comerciantes mexicanos, sino también peruanos. Todos ellos traían abundante plata (que el galeón transportaba a Manila en su tornaviaje) para la compra de las mercancías que luego distribuían a lo largo y ancho del territorio americano, sin atender a la legalidad restrictiva sancionada por la Administración colonial. El gran damnificado de las operaciones pacíficas, hasta la irrupción de ciertos cambios acaecidos a mediados del siglo xvIII, fue el comercio atlántico de las flotas de Nueva España y los galeones de Tierra Firme, es decir, el comercio sevillano/gaditano. Los grandes beneficiados, cómo no, fueron los comerciantes americanos, ya que pudieron operar en sus propios términos al margen del control de la metrópoli. Haciendo gala de la sagacidad propia de un avezado detective, esta historia nos la había contado Bonialian en sus dos libros anteriores ${ }^{1}$. En La América española: entre el Pacífico y el Atlántico, el historiador argentino retoma los argumentos desarrollados en publicaciones previas para integrarlos en un único relato que, además, alarga el arco temporal hasta 1840.

Tras una introducción que explica los cuatro ejes geohistóricos objeto de examen, el libro está estructurado en dos partes bien definidas. La primera, formada de dos capítulos, se titula «El Atlántico pacificado» y cubre el periodo 1580-1740. El primer capítulo analiza la preponderancia de los comerciantes peruleros tanto en el comercio del Perú con Acapulco (y por extensión con Manila, a través del puerto novohispano) como en los intercambios transatlánticos con Sevilla entre 1580 y

\footnotetext{
1 Bonialian, M., El Pacífico hispanoamericano: política y comercio asiático en el Imperio español, 1680-1784 (México, El Colegio de México, 2012); idem, China en la América colonial: bienes, mercados, comercio y cultura del consumo desde México hasta Buenos Aires (México, Instituto Mora, 2014).
}

1620. El boom de la producción de plata en Potosí fue el principal responsable de ese protagonismo marcadamente limeño. Bonialian opina que la autonomía mercantil lograda fue tanta que «la posibilidad del quiebre [comercial] entre España y el espacio peruano resulta comprensible» (pág. 123). Aquí el libro toma el testigo de los trabajos de Margarita Suárez, Enriqueta Vila y Lutgardo García Fuentes, entre otros. El segundo capítulo da un salto en el tiempo para arrancar en 1680 y concluir en 1740. Ahora los principales protagonistas pasan a ser los comerciantes novohispanos, apoyados en la recuperación demográfica del virreinato y en el despegue de su minería de plata. El comercio del galeón, cuya titularidad oficial recaía en los vecinos de Manila, pasó a estar controlado enteramente por los almaceneros de México. Los intercambios del virreinato novohispano con el Perú continuaron siendo importantes, pero los peruleros ya no desempeñaban el papel dominante de antaño. El descenso y estancamiento de la producción argentífera de la provincia de Charcas los limitó en cierta medida, aunque también el que la navegación mercantil francesa se adentrara en aguas del Pacífico en las dos primeras décadas del siglo xviI, hecho al que Bonialian podía haber prestado más atención.

La segunda parte del libro, compuesto de un único capítulo, refiere una profunda mutación iniciada en la década de 1740 y que, en dos fases, produjo "El Pacífico atlantizado". En realidad, las dos fases de la atlantización merecían sendos capítulos, aunque solo fuera por establecer cierta simetría con el periodo anterior. La apertura oficial de la ruta del Cabo de Hornos por medio de navíos de registro hizo que los comerciantes gaditanos accedieran a la costa pacífica con creciente frecuencia. Paralelamente, el galeón de Manila comenzó su lento declive. Desde ese momento el Pacífico dejó de ser un lago indiano para pasar a estar controlado por intereses peninsulares, atlánticos. Pero también esos intereses se verían gradualmente alterados a partir de 1790, cuando navíos británicos y estadounidenses dedicados a la explotación de aceite de ballena comenzaron a infestar las costas occidentales de la América española. Sus expediciones encubrían intercambios comerciales directos con las colonias. Poco después, a los balleneros le siguió el comercio de neutrales y, una vez iniciadas las guerras de independencia hispanoamericana, la llegada de multitud de barcos mercantes británicos cargados de baratas manufacturas textiles. Esta segunda fase de la atlantización del Pacífico irrumpió con una nueva ruta incursora: el eje Jamaica-Panamá-San Blas precipitó la crisis del histórico eje terrestre Ciudad de México-Acapulco-Veracruz. Ya no eran únicamente las costas peruanas las afectadas por el comercio extranjero en el Pacífico; le había llegado el turno a Nueva España y, tras 1821, también a su sucesor, el México independiente.

Como se puede apreciar, con este libro Bonialian se lanza a cortar mucha tela, lo cual es sin duda valiente y meritorio, pues 
la historia de largo recorrido, tan necesaria, viene padeciendo una salud débil desde hace ya algunos años. El libro se destaca por combinar con solvencia la síntesis historiográfica con la investigación original realizada en múltiples archivos americanos y españoles. Habla del papel destacado que jugó la América española en la globalización temprana como puente entre dos océanos, aunque la situación geográfica del continente explica solo parte de su trascendencia. Otro factor, igualmente importante y que Bonialian no olvida, provino de la enorme producción argentífera de ambos virreinatos, auténtico lubricante del comercio intercontinental y global. Y un tercer factor sobre el que el autor incide acertadamente, siguiendo la estela de los trabajos de Carlos Assadourian, fue el del desarrollo de las grandes economías regionales hispanoamericanas, ya que alteraron y redirigieron importantes ejes comerciales.

Es muy difícil que un libro con tan extenso recorrido cronológico y que aborda tantos temas esté exento de aspectos criticables, aunque en este caso las objeciones de ninguna manera desvirtúan los argumentos principales, que son verdaderamente sugerentes. Lo más llamativo es el silencio casi total sobre el periodo 1620-1680, el cual se convierte en una suerte de caja negra; Bonialian nos cuenta cómo se llega y cómo se sale de él, pero no lo que ocurre en su interior. ¿Qué lugar ocupa lo acaecido durante esas décadas dentro del marco interpretativo propuesto? Esa inclusión no habría alterado la estructura del libro, pues hubiese bastado con retrasar la cronología del primer capítulo hasta 1650 e iniciar el segundo en ese mismo año en lugar de 1680 , librando así al texto de una ausencia demasiado presente.

Otro aspecto discutible, hasta cierto punto, es el del empleo acrítico de algunas fuentes primarias. Un estudio que incide en la importancia del contrabando y el fraude está por fuerza obligado a recurrir a fuentes de naturaleza mayormente cualitativa. Así lo hace Bonialian. Sin embargo, es necesario tener muy presente que las observaciones de testigos y protagonitas de la época son a menudo interesadas y sesgadas. Los memoriales, los arbitrios y la correspondencia oficial sobre temas económicos habitualmente rezuman un victimismo de tintes apocalípticos. Las quejas de la Audiencia de Panamá en la primera década del siglo xviI sobre el estado de la región son un ejemplo de ello. A partir de las quejas de los panameños, Bonialian concluye que Portobelo había adquirido una imagen "francamente miserable» (pág. 67), dando a entender que los tratos entre peninsulares y peruanos estaban disminuyendo. Pero una mirada a los datos proporcionados por los Chaunu muestra que la tendencia del tonelaje de las flotas (el valor declarado de las mismas sirve de bien poco) que llegaban a Portobelo (cuyo pico fue alcanzado en el quinquenio 16261630) se mantuvo, con altibajos, bastante estable desde 1580 hasta 1630 , a pesar del espaciamiento entre flotas ${ }^{2}$. Es decir, si atendemos a los datos oficiales, el riesgo de desconexión transatlántica sobre el que tanto incide el primer capítulo del libro para el caso peruano en realidad no parece haber existido en las décadas iniciales del siglo xviI. Ese argumento habría encontrado terreno mejor abonado en el periodo posterior a 1630 .

Tal como indica el autor en la introducción, las ideas expuestas son "provisorias y abiertas a la discusión» (pág. 13). Promover un debate interesante está al alcance de pocos libros. El de Bonialian es uno de ellos. Recomiendo su lectura sin reservas.

Xabier Lamikiz Universidad del País Vasco (UPV/EHU)

https://doi.org/10.33231/j.ihe.2020.01.006
${ }^{2}$ Chaunu, H. y Chaunu, P., Seville et l'Atlantique, 1504-1650, vol. 6 (París, S.E.V.P.E.N., 1956), p. 671. 